\title{
Evaluation of Notch3 Deficiency in Diabetes-Induced Pericyte Loss in the Retina
}

\author{
Hua Liu ${ }^{a, b}$ Wenbo Zhang ${ }^{a, c}$ Brenda Lilly ${ }^{d-f}$ \\ a Department of Ophthalmology and Visual Sciences, University of Texas Medical Branch, Galveston, TX, USA; \\ ${ }^{b}$ Center for Biomedical Engineering, University of Texas Medical Branch, Galveston, TX, USA; ${ }^{\circ}$ Departments of \\ Neuroscience, Cell Biology and Anatomy, University of Texas Medical Branch, Galveston, TX, USA; ${ }^{\mathrm{d}}$ Center for \\ Cardiovascular Research, Columbus, OH, USA; ${ }^{\circledR}$ The Heart Center, Nationwide Children's Hospital, Columbus, \\ $\mathrm{OH}, \mathrm{USA} ;{ }^{\mathrm{f}}$ Department of Pediatrics, The Ohio State University, Columbus, OH, USA
}

\section{Keywords}

Notch3 $\cdot$ Pericytes $\cdot$ Notch signaling $\cdot$ Diabetic retinopathy $\cdot$ Ins2Akita

\begin{abstract}
Loss of vascular pericytes has long been associated with the onset of diabetic retinopathy; however, mechanisms contributing to pericyte dropout are not understood. Notch 3 has been implicated in pericyte stability and survival, and linked to vascular integrity. Notch3 mutant mice exhibit progressive loss of retinal pericytes. Given that diabetic retinopathy is associated with pericyte loss, we sought to determine whether perturbation of Notch3 signaling contributes to diabetes-induced pericyte dropout and capillary degeneration. We utilized a pericyte-expressed LacZ transgene (XlacZ4) to examine pericyte loss in retinas of a type I diabetic mouse model (Ins2Akita) and Notch3-deficient mice. Notch3 null animals showed a dramatic loss of the LacZ marker by 8 weeks of age, while Ins2Akita diabetic and Notch3 heterozygous mice exhibited a much slower and subtler loss of LacZ. Although combined Notch3 heterozy-
\end{abstract}

\section{KARGER}

(c) 2018 S. Karger AG, Basel

E-Mail karger@karger.com

www.karger.com/jvr gosity in Ins2Akita diabetic animals did not show further deficits, the trypsin digest method revealed that Notch3 haploinsufficiency increased the formation of acellular capillaries in diabetic mice. Our data further indicate that Notch signaling is blunted in diabetic retinas and in cells exposed to hyperglycemia. These results are the first to demonstrate an association between Notch3 signaling, pericyte loss, and diabetic retinopathy.

(c) 2018 S. Karger AG, Basel

\section{Introduction}

Diabetic retinopathy is a major health concern for people with all types of diabetes $[1,2]$ and affects $5.4 \%$ of the US population aged 40 years and older. If untreated the disease leads to blindness [3]. One third of patients diagnosed with diabetes have some stage of diabetic retinopathy [4]. The disease is characterized by morphologic changes to the microvessels that include aberrant tight junctions, thickening of the basement membrane, loss of pericytes and formation of acellular capillaries that leads
Dr. Brenda Lilly

Center for Cardiovascular Research and The Heart Center Nationwide Children's Hospital, Room WB4233 700 Children's Drive, Columbus, OH 43205 (USA)

E-Mail brenda.lilly@ nationwidechildrens.org 
to increased vascular permeability, retinal ischemia, and microaneurysms $[1,5]$. One of the earliest events in diabetic retinopathy is pericyte loss or dropout, which contributes to vascular instability and disease progression [5-7]. Understanding what promotes this critical step and identifying ways to prevent pericyte dropout is an important component in controlling disease progression. However, the mechanistic link between diabetes, hyperglycemia and pericyte loss is not well defined.

Retinal pericytes are vascular support cells that surround the endothelial cell-lined vessels and provide stability and tone to promote proper blood flow $[6,8,9]$. They also serve an important role in maintenance of the blood-retina barrier and are a critical part of the neurovascular unit by regulating permeability, clearance of toxic metabolites, and neuroinflammation [10, 11]. While pericyte loss or disruption has been linked to an array of diseases, including fibrosis and cerebral autosomal dominant arteriopathy with subcortical infarcts and leukoencephalopathy (CADASIL) $[9,12]$, it is unequivocally tied to diabetic retinopathy and is one of the earliest morphological indicators of the disease [5-7]. Some evidence has linked hyperglycemia to the cause of pericyte loss, with some indication that it is a result of increased reactive oxygen species $[1,8,13]$. Despite these important studies, the direct mechanisms contributing to pericyte dropout remain elusive.

Genetic and molecular approaches have identified certain pathways that contribute to pericyte homeostasis and function. Ligand/receptor combinations from the platelet-derived growth factor- $\beta$, transforming growth factor- $\beta$, and angiopoietin- 1 signaling families are known to contribute to pericyte recruitment, migration, and stability $[9,11,13]$. Additionally, the Notch signaling pathway has also been linked to pericyte differentiation and survival [14-17]. The Notch3 receptor is enriched in vascular smooth muscle cells and pericytes, and is the causative gene of CADASIL, which is an autosomal dominant stroke disorder resulting in vascular dementia $[18,19]$. Genetic deletion studies have revealed its importance in smooth muscle maturation and homeostasis and bloodbrain barrier function $[16-18,20]$. In the retina, Notch 3 is expressed in pericytes [21-23], and genetic deficiency results in progressive loss of retinal pericytes, which is linked to its role in cell survival $[23,24]$.

In this study we examined the relationship of pericyte loss in Notch3 deficiency and diabetes. Using a pericyteexpressed LacZ transgene (XlacZ4) [25], we show that Notch 3 null mice have substantially reduced expression of the transgene at 8 weeks of age, while heterozygous
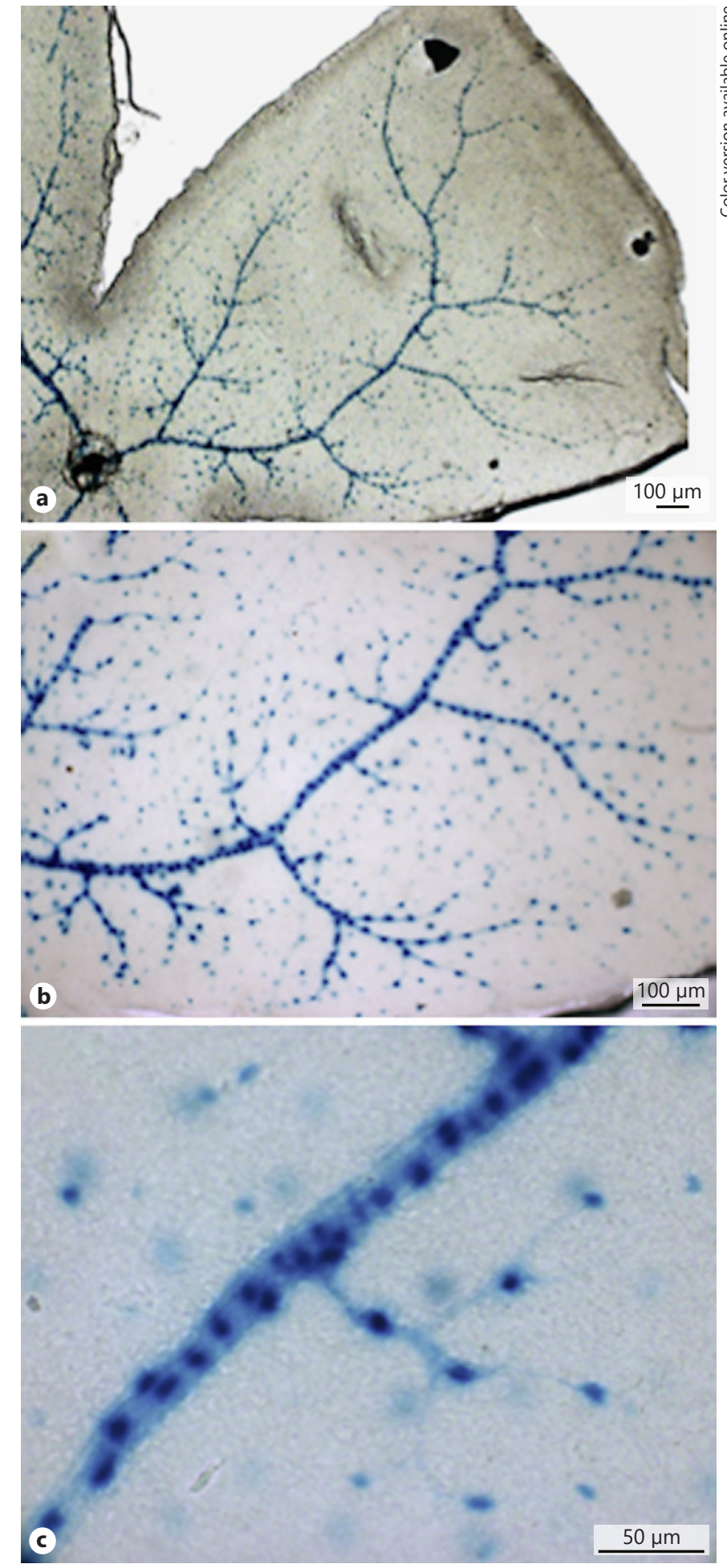

Fig. 1. Smooth muscle cell/pericyte-specific reporter XlacZ4 highlights the vasculature in the retina. Retinas were isolated from adult mice harboring the XlacZ4 transgene, subjected to staining for $\beta$-galactosidase ( $\mathrm{LacZ}$ ) and flat mounted for imaging. a-c Transgene expression at increasing magnification. 


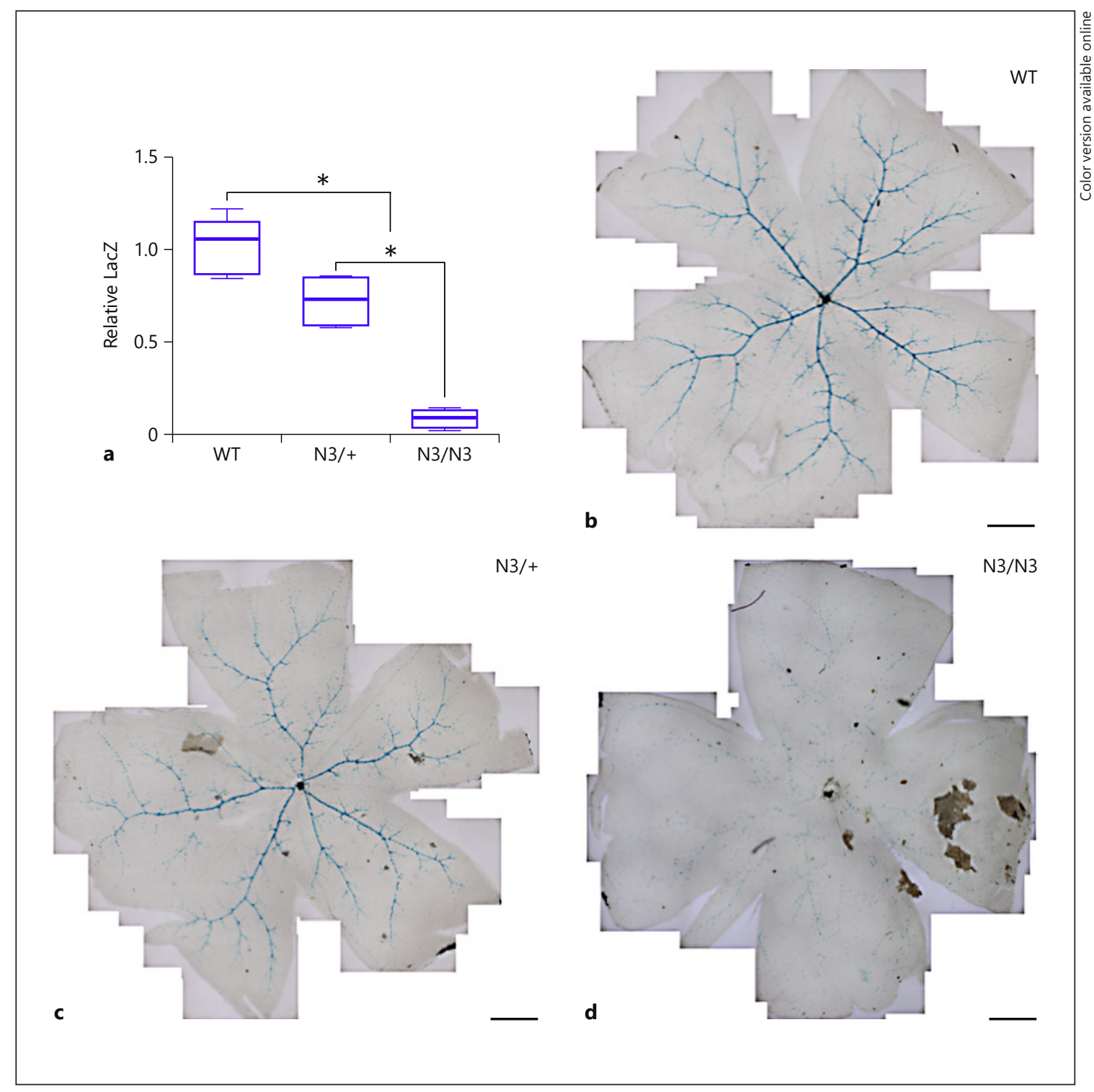

Fig. 2. XlacZ4 transgene expression is decreased in Notch3-deficient mice. Retinas from 8-week old wild-type (WT), Notch3 ${ }^{+/-}(\mathrm{N} 3 /+)$, and Notch3 ${ }^{-/}(\mathrm{N} 3 / \mathrm{N} 3)$ mice harboring the XlacZ4 transgene were isolated and stained for LacZ activity. a Graph of relative LacZ expression from indicated genotypes with wild-type control reference sample set to 1 . b-d Representative images of flat-mounted retinas from WT, N3/+, and N3/N3 mice stained for LacZ activity. Scale bar $=500 \mu \mathrm{m} .{ }^{*} p<0.05$ versus relative controls; $n=4$.

mice exhibit a much slower and progressive loss of the LacZ expression. Evaluation of LacZ expression in the type I diabetic Ins $2^{\text {Akita }}$ mice [26-28] showed reduced expression that parallels that of Notch 3 haploinsufficiency; however, examination of Notch 3 haploinsufficiency in Ins $2^{\text {Akita }}$ diabetic mice revealed no association. Utilization of trypsin digest to evaluate acellular capillaries demonstrated that Notch 3 heterozygosity did not significantly increase acellular capillaries, while the Ins $2^{\text {Akita }}$ diabetic mice had significant increases in acellular capillaries at 24 weeks of age. Importantly, Notch 3 haploinsufficiency further increased acellular capillaries in the Ins $2^{\text {Akita }}$ diabetic mice. Evaluation of Notch signaling components in diabetic mice showed alterations in select transcripts, and in vitro experiments to evaluate Notch activity in cocultured vascular cells indicated that Notch signaling is blunted by hyperglycemia. 


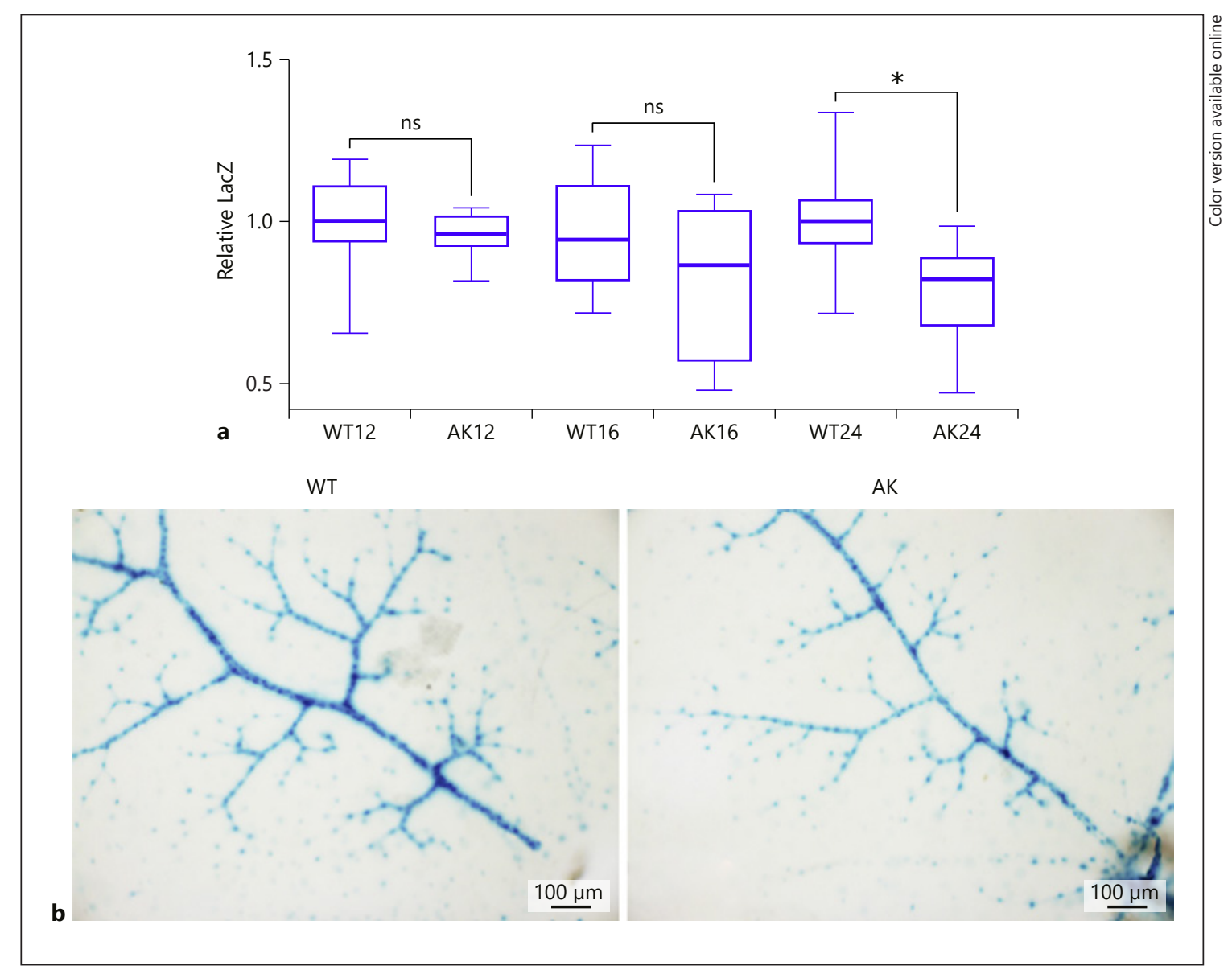

Fig. 3. Pericyte coverage is decreased in aged diabetic Ins $2^{\text {Akita }}$ mice. Detection of pericytes as monitored by the XlacZ4 transgene in aged diabetic Ins $2^{\text {Akita }}$ mice. LacZ was quantified in pericytes of wild-type (WT) and diabetic Ins $2^{\text {Akita }}(\mathrm{AK})$ mice at 12,16 , and 24 weeks of age. a Graph of relative LacZ expression at indicated time points. $\mathbf{b}$ Representative images of WT and AK retinas at 24 weeks of age. Scale bar $=100 \mu \mathrm{m} .{ }^{*} p<0.05$ versus relative controls; ns, not significant; $n=6$.

\section{Results}

Notch3 Deficiency Causes a Dose-Dependent Decrease in XlacZ4 Transgene Expression

Previously, others and we demonstrated that Notch 3 mutant mice have progressive loss of retinal pericytes and smooth muscle cells $[16,17,23,24]$. As a simple method to track pericyte loss, we utilized an XLacZ4 transgenic mouse line (B6.FVB-Tg(Fabp4-lacZ)4Mosh/J, Stock No.: 018625) [25], which expresses the LacZ reporter gene under the control of a smooth muscle- and pericyte-specific promoter, to demarcate retinal pericytes (Fig. 1) [29, 30]. The XLacZ4 transgenic mice were crossed with mice harboring the Notch 3 null mutation (Notch $3^{-/-}$), and LacZ expression was evaluated in retinas of mice at 8 weeks of age. LacZ staining in flat-mounted retinas revealed that in the absence of functional Notch 3 there was a dramatic loss of the XlacZ4 transgene expression, compared to the wild-type control (Fig. 2) (WT $1.02 \pm 0.152, \mathrm{~N} 3 / \mathrm{N} 30.09$ $\pm 0.052)$. Notch $^{+/-}$retinas showed a less severe loss of LacZ transgene expression ( $\mathrm{N} 3 /+0.73 \pm 0.136)$, but staining was still significantly reduced and distinguishable from wild-type and $\mathrm{Notch}^{-/-}$mice (Fig. 2). Thus, the XLacZ4 transgene exhibited Notch3-reliant expression that was dose-dependent and consistent with the loss of pericytes.

\section{Analysis of Pericytes and Acellular Capillaries in Diabetic Mice with Notch3 Deficiency}

Ins $2^{\text {Akita }}$ mice are an established model of type I diabetes and have been shown to have pericyte dropout [26-28, 31,32 ]. Ins $2^{A k i t a}$ male mice become hyperglycemic at 4 


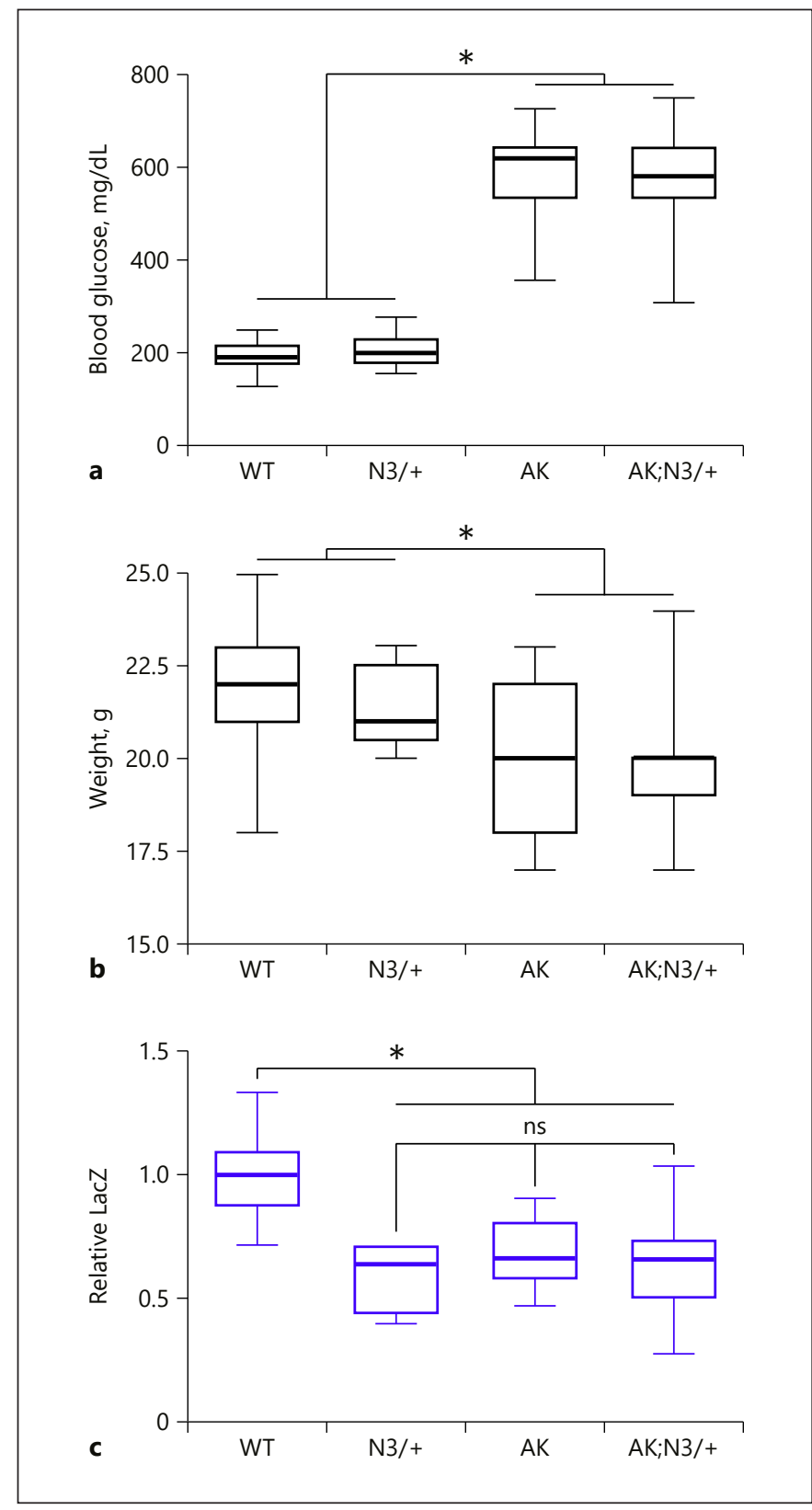

Fig. 4. Characterization of combined Ins $2^{\text {Akita }}$ and Notch 3 deficiency. Blood glucose measurements (a) and body weights (b) of wildtype (WT), Notch $3^{+/-}(\mathrm{N} 3 /+)$, Ins $2^{\text {Akita }}(\mathrm{AK})$, and Ins $2^{\text {Akita }} ;$ Notch $^{+/-}$ $(\mathrm{AK} ; \mathrm{N} 3 /+)$ mice. $\mathrm{c} \mathrm{LacZ}$ activity measured in indicated genotypes. ${ }^{*} p<0.05$ versus relative controls; ns, not significant; $n \geq 7$.

weeks of age and begin to develop retinal complications at 12 weeks [26-28]. Using the XlacZ4 transgene we evaluated pericytes in Ins $2^{\text {Akita }}$ diabetic mice at 12, 16, and 24 weeks of age. Quantification of LacZ staining revealed no significant difference in pericyte numbers between wildtype and diabetic mice at 12 and 16 weeks (Fig. 3a); how- ever, there was a significant decrease in LacZ staining at 24 weeks (Fig. 3a, b) (WT24 $1.0 \pm 0.131$, AK24 $0.78 \pm$ 0.142). At 24 weeks the vessels of the diabetic mice appeared thinner, with less LacZ-positive pericytes at the periphery of the blood vessels.

Given that the XlacZ4 transgene could detect pericyte loss in both Notch3-deficient and Ins $2^{\text {Akita }}$ diabetic mice, we next tested whether the combination of Notch 3 deficiency and diabetes would show an exacerbated loss of pericytes at 24 weeks. Because Notch 3 homozygous null mice have severe pericyte loss prior to the onset of a diabetic phenotype in Ins $2^{A k i t a}$ animals, we utilized Notch3 heterozygous mice to cross with Ins $2^{\text {Akita }}$ mice for these analyses. Comparing blood glucose and body weights of control and Ins $2^{A k i t a}$ mice showed the expected increase and decrease in these parameters. Importantly, the combined $\mathrm{Notch}^{+/-}$;Ins2 ${ }^{\text {Akita }}$ mice were not statistically different from Ins $2^{\text {Akita }}$ animals (Fig. 4a, b). Evaluation of the pericyte population with the XlacZ4 transgene revealed that compared to Notch $3^{+/-}$and Ins $2^{\text {Akita }}$, the combined Notch $3^{+/-}$; Ins $2^{\text {Akita }}$ mice were not significantly different. Compared to the wild-type control, all 3 genotypes $\left(\right.$ Notch $^{+/-}$, Ins $2^{\text {Akita }}$, and Notch ${ }^{+/-}$; Ins $\left.2^{\text {Akita }}\right)$ were different from control, but not from one another (Fig. 4c) (WT $1.00 \pm 0.159, \mathrm{~N} 3 /+0.59 \pm 0.124, \mathrm{AK} 0.68 \pm 0.147, \mathrm{AK} ; \mathrm{N} 3$ $0.63 \pm 0.212$ ). The reduced $X l a c Z 4$ transgene expression may reflect pericyte injury rather than pericyte loss based on evidence that this marker is downregulated in response to mechanical vascular injury $[11,25]$.

In diabetic retinopathy, pericyte loss is accompanied by acellular capillary formation [26, 33]. Acellular capillaries are basement membrane tubes without cell nuclei that have at least one fourth of the normal capillary diameter $[26,33]$. To further examine the consequence of Notch 3 deficiency in diabetic mice, we utilized trypsin digestion to quantify acellular capillaries of the retina. Interestingly, at 24 weeks Notch $3^{+/-}$retinas were indistinguishable from wild-type controls (Fig. 5a, b). Conversely, Ins $2^{\text {Akita }}$ mice exhibited an increase in acellular capillaries, which was exacerbated in the Notch $3^{+/-}$; Ins $2^{\text {Akita }}$ mice (Fig. 5a, b) (WT $49.35 \pm 1.46, \mathrm{~N} 3 /+51.55 \pm$ 4.62, AK $69.4 \pm 4.33$, AK;N3 $89.75 \pm 3.12$ ).

\section{Notch Signaling Is Perturbed by Hyperglycemia}

To determine whether diabetic conditions affect Notch signaling, we evaluated expression by quantitative (q) PCR in whole retinas of wild-type and Ins $2^{\text {Akita }}$ mice at 24 weeks of age. Notch3 and jagged 1 (Jag1) have been characterized as the major receptor/ligand pair that facilitates endothelial cell-pericyte interactions [34-36]. Expression 
Fig. 5. Acellular capillaries are reduced in Notch3-deficient and diabetic Ins $2^{\text {Akita }}$ mice. Retinas were collected from 24-weekold wild-type (WT), Notch ${ }^{+/-}(\mathrm{N} 3 /+)$, Ins $2^{\text {Akita }}(\mathrm{AK})$, and Ins $2^{\text {Akita }}$ Notch $3^{+/-}$ $(\mathrm{AK} ; \mathrm{N} 3 /+)$ mice. Retinal trypsin digestion was performed to detect the change of acellular capillaries. Pictures were taken under a light microscope at $200 \times$ magnification, and acellular capillaries were quantified in 8 midretinal fields and averaged. a Number of acellular capillaries per field in the midretinas of indicated genotypes. b Representative images of trypsin digests from indicated genotypes. Arrows indicate acellular capillaries. Scale bar $=25 \mu \mathrm{m}$. ${ }^{*} p<$ 0.05 versus relative controls; ns, not significant; $n=5$.

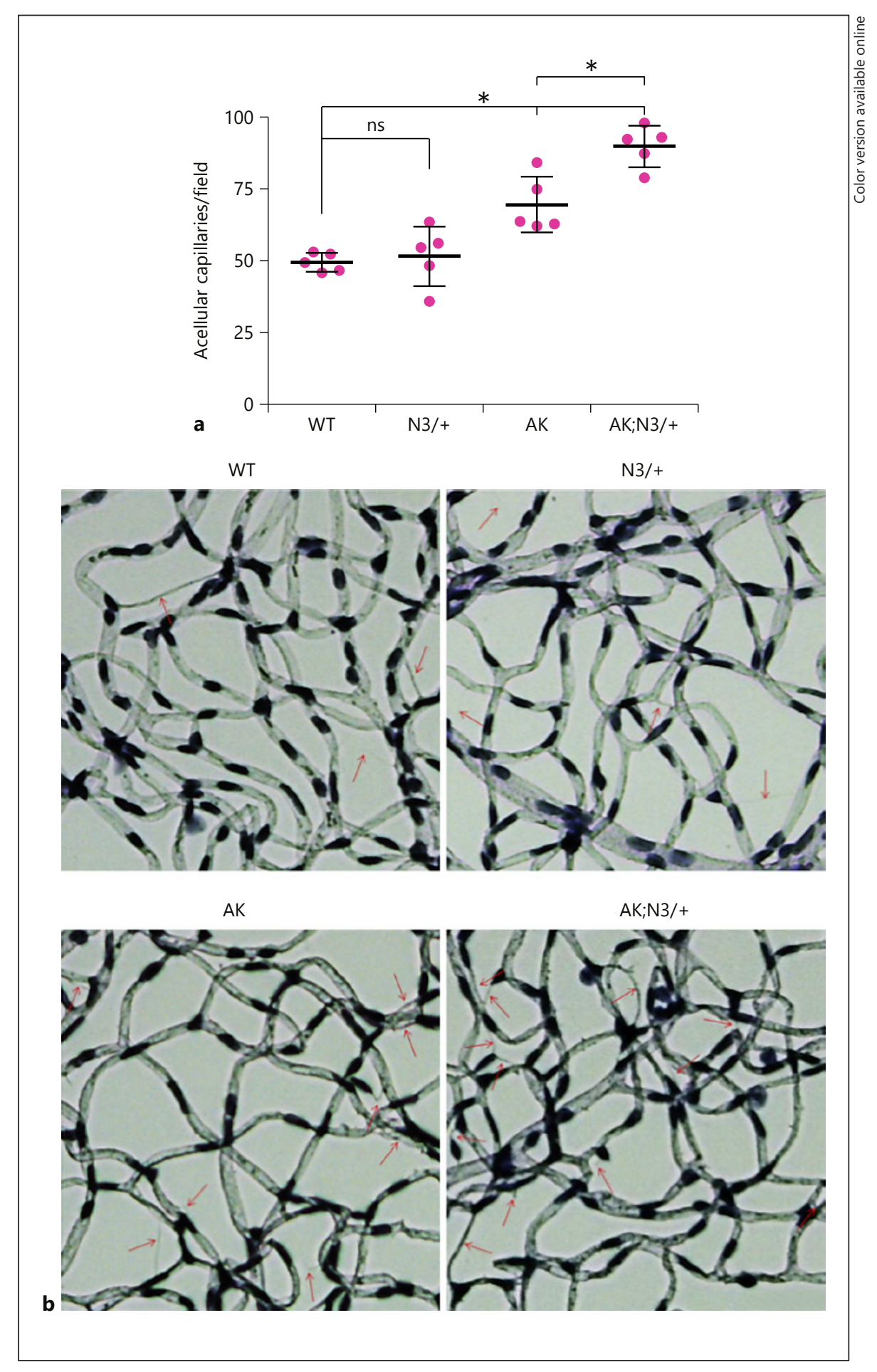

analysis of Notch3 showed no significant difference between control and diabetic mice, while the Jag1 ligand exhibited increased expression in retinas of Ins $2^{\text {Akita }}$ mice (Fig. 6a). Downstream targets, Hes 1 and smooth muscle a-actin (Acta2), showed a significant decrease in the dia- betic retinas, whereas HeyL was not changed (Fig. 6b). These data indicate that Notch signaling is altered in diabetes, and that certain Notch components may be selectively targeted. Previously our lab demonstrated that endothelial cells via the Jag1 ligand increase Notch 3 expres- 




Fig. 6. Select Notch signaling components are perturbed in diabetic mice. qPCR to detect expression of Notch signaling genes from retinas of wild-type (WT) and diabetic Ins $2^{\text {Akita }}(\mathrm{AK})$ mice relative to Rpl13A as reference gene. a Receptor, Notch3 and ligand, Jag1. b Notch-dependent downstream genes, Hes1, HeyL, and smooth muscle $\alpha$-actin (Acta2). ${ }^{*} p<0.05$ versus relative controls; ns, not significant; $n=12$.

sion and activate Notch signaling in cocultured smooth muscle cells and pericytes [36]. Using a Notch-sensitive luciferase reporter transfected into human retinal pericytes, we can measure endothelial cell-dependent Notch activation in a cell-specific manner (Fig. 7a). To evaluate whether Notch activation is influenced by hyperglycemia, we measured Notch signaling in transfected retinal pericytes cultured alone or with human retinal endothelial cells in normal and high glucose conditions. The data show that Notch activation by cocultured endothelial cells is blunted by hyperglycemia (Fig. 7b) (cocultured low glucose $5.6 \pm 1.81$, cocultured high glucose $4.3 \pm$ 2.13). We also examined the expression of Notch3 or Jag1 in hyperglycemic conditions but did not observe signifi-

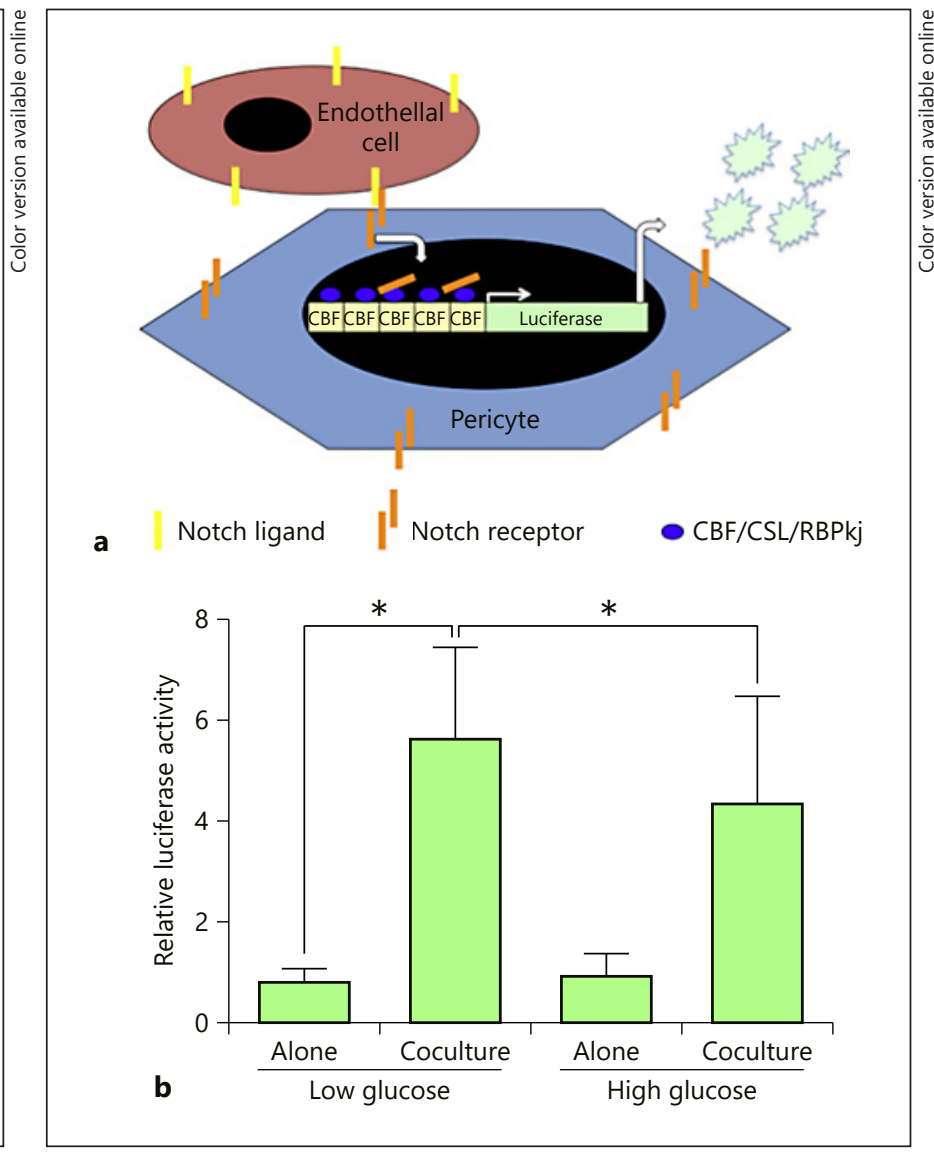

Fig. 7. Endothelial cell-pericyte Notch signaling is blunted in hyperglycemia. a Diagram of Notch sensor $(5 \times \mathrm{CBF})$ luciferase assay used to detect Notch activity in cocultured human retinal pericytes. Pericytes were transfected with the Notch sensor prior to culturing with or without human retinal endothelial cells in low (5 $\mathrm{mM})$ or high $(25 \mathrm{mM})$ glucose for $48 \mathrm{~h}$. b Robust induction of Notch activity in pericytes by cocultured endothelial cells, which is blunted in the presence of hyperglycemia. ${ }^{*} p<0.05$ versus relative controls; $n=4$.

cant differences (not shown), suggesting that expression does not reflect Notch activity. These data, together with the decrease in Notch target genes in diabetic mice suggests that Notch signaling is perturbed by diabetes.

\section{Materials and Methods}

Mice

All strains were obtained from Jackson Laboratory and maintained in C57BL/6 background: Notch3 (B6;129S1-Notch $3^{\mathrm{tm} 1 \text { Grid/J, }}$

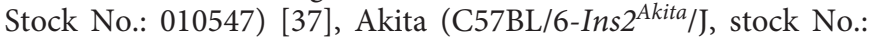
003548) [26], XLacZ4 (B6.FVB-Tg(Fabp4-lacZ)4Mosh/J, Stock No.: 018625) [25]. Genotyping of mice was carried out by PCR following Jackson Laboratory protocols. All mouse studies were per- 
formed in accordance with protocols approved by the Institutional Animal Care and Use Committee at the Research Institute at Nationwide Children's Hospital. For experiments with diabetic mice, only heterozygous Ins $2^{\text {Akita }}$ male mice were used, with wildtype male mice used as controls. Age-matched mice were grouped and evaluated based on relevant genotypes. Blood glucose was measured following an 8-hour fasting period using tail vein blood with AlphaTrak 2 Blood Glucose Strips (Abbott) and Glucometer. Experimental groups of mice were weighed every week after weaning on a consistent schedule.

\section{LacZ Staining on Whole-Mount Retinas}

For staining of $\beta$-galactosidase activity, eyes were isolated from mice at indicated time points and fixed in $2 \%$ formaldehyde (Fisher) plus $0.2 \%$ glutaraldehyde (Sigma) for $30 \mathrm{~min}$. The cornea and lens were removed, and retinas were placed in staining solution overnight at room temperature. The staining solution to detect LacZ activity consisted of $5 \mathrm{mM} \mathrm{K}_{4} \mathrm{Fe}(\mathrm{CN})_{6}, 5 \mathrm{mM} \mathrm{K}{ }_{3} \mathrm{Fe}(\mathrm{CN})_{6}$, $2 \mathrm{mM} \mathrm{MgCl}_{2}, 0.02 \% \mathrm{NP}-40$, and $0.1 \% \mathrm{X}$-gal in PBS buffer (all chemicals from Sigma). After staining, retinas were postfixed with $4 \%$ formaldehyde overnight. The remaining sclera and vitreous were removed to isolate retinas, and radial incisions were made at equal intervals along the retinal edge. Retinas were flat mounted with Vectashield (Vector Laboratories). LacZ images were captured using a Zeiss AXIO microscope with ZEN pro software and equivalent settings. LacZ was quantified with NIH ImageJ software using a fixed threshold to measure colored pixels. Relative LacZ expression is graphed with a wild-type control reference sample set to 1 .

\section{Trypsin Digestion of Mouse Retina and Staining}

Eyes were fixed in $2 \%$ paraformaldehyde at room temperature overnight. On the second day, retinas were isolated and digested in $3 \%$ Difco Trypsin 250 (BD Biosciences) for $6 \mathrm{~h}$ at $37^{\circ} \mathrm{C}$. After careful removal of internal limiting membranes, the neuroretinal tissue was gently brushed away. Next, retinas were allowed to stand in $0.5 \%$ Triton X-100 solution until the complete removal of neurons. Preparations of retinal vascular networks were set onto glass microscope slides in distilled water, air-dried and stained with periodic acid-Schiff and hematoxylin for histologic evaluation. Acellular capillaries were counted at $200 \times$ magnification in 8 fields per retina in multiple midretinal areas and averaged.

RNA Isolation and $q P C R$

Total RNA was extracted from mouse retinas using TissueLyser (Qiagen) homogenation in TRIzol (Invitrogen) according to the manufacturer's instructions. RNA was reverse transcribed with M-MLV reverse transcriptase (Promega) to generate cDNA. qPCR was performed using a StepOne PCR system (Applied Biosystems) with Power SYBR Green. The relative difference in various transcripts was calculated by the $\Delta \Delta \mathrm{C}_{\mathrm{T}}$ method using ribosomal protein L13a (Rpl13A) as the internal control/reference gene. Primer sequences for mouse transcripts were as follows: Notch 3 forward 5'-TTG TCT GGA TGG AAG CCC ATG T-3'; Notch3 reverse $5^{\prime}$ ACT GAA CTC TGG CAA ACG CCT-3'; Jag1 forward $5^{\prime}$-GGC TTC TCA CTC AGG CAT GAT A-3'; Jag1 reverse 5'-GTG GGC AAT CCC TGT GTT TT-3'; Hes1 forward 5'-CCC CAG CCA GTG TCA ACA C-3'; Hes1 reverse 5'-TGT GCT CAG AGG CCG TCT T-3'; HeyL forward 5'-CGC AGA GGG ATC ATA GAG AAA CG-3'; HeyL reverse $5^{\prime}$-GCC AGG GCT CGG GCA TCA AAG AA-3'; Acta2 forward $5^{\prime}$-TCC TGA CGC TGA AGT ATC
CGA TA-3'; Acta2 reverse $5^{\prime}$-GGT GCC AGA TCT TTT CCA TGT C-3'; Rpl13A forward 5' -TCC CTG CTG CTC TCA AGG-3'; Rpl13A reverse $5^{\prime}$-GCC CCA GGT AAG CAA ACT T-3'.

\section{Cell Culture}

Primary human retinal pericytes (Cell-Systems) were grown in Dulbecco's modified Eagle's medium (Mediatech Inc.) supplemented with $5 \%$ fetal bovine serum (Hyclone), $2 \mathrm{mM}$ glutamine, $1 \mathrm{~mm}$ sodium pyruvate, and $100 \mathrm{U} / \mathrm{mL}$ penicillin-streptomycin. Primary human retinal microvascular endothelial cells (Cell-Systems) were maintained in EBM-2 media (Lonza) supplemented with the bullet kit as recommended. Cells between passages 6 and 9 were used for all experiments. All cultures were maintained in humidified $5 \% \mathrm{CO}_{2}$ at $37^{\circ} \mathrm{C}$.

\section{Plasmid Transfection and Reporter Assays}

A Notch sensor containing $5 \times \mathrm{CBF} 1$ binding sites upstream of the luciferase reporter was generated as described [36, 38]. For normalizing transfection efficiency, CMV promoter-driven secreted embryonic alkaline phosphatase (SEAP) (Addgene: \#24595) reporter plasmid was cotransfected with the luciferase reporter [38]. To measure Notch transcriptional activity, retinal pericytes at $80 \%$ confluency were transfected with the reporter plasmids using Lipofectamine 3000 (Invitrogen). Following transfection, pericytes were cultured in media with high $(25 \mathrm{mM})$ or low $(5 \mathrm{mM})$ glucose, and retinal endothelial cells were added to select wells for coculture and activation of Notch signaling for $48 \mathrm{~h}$. All coculture and control alone experiments were performed in media consisting of EBM-2 supplemented with the bullet kit and indicated glucose concentration. Luciferase activity was measured with the BrightGlo assay kit (Promega), and SEAP activity was measured with a Phospha-Light System (Applied Biosystems). Activity was quantified using a Molecular Devices SpectroMax luminometer $[36,38]$. All experiments were performed in duplicate and repeated a minimum of 3 times.

\section{Statistical Analysis}

Data analyses were performed using GraphPad Prism. Comparisons between data sets were made using Student's $t$ test or ANOVA, with differences considered significant if $p<0.05$. Data are presented as means $\pm \mathrm{SD}$, unless otherwise indicated. Data shown are representative of at least 3 independent experiments, and/or the $n$ value is indicated with data.

\section{Discussion}

Diabetic retinopathy is one microvascular complication associated with diabetes and a leading cause of blindness $[1,2]$. One of the first indicators of diabetic retinopathy is a loss of pericytes surrounding the blood vessels. This leads to progression of the disease that includes increased vascular permeability, capillary degeneration, retinal microaneurysms and hemorrhage, and devolves into the proliferative stage, which ultimately leads to blindness [5-7]. While pericyte dropout is a defining feature of the early stages of the disease, the mechanisms that 
contribute to this important step are not known. Data from several labs have demonstrated that Notch signaling, in particular the Notch 3 receptor, is essential for pericyte stability and survival, and therefore seemed a likely candidate as a contributor to diabetes-induced pericyte loss [14-17, 23]. To examine this possible link, we examined pericyte loss in Notch 3 mutant and diabetic mouse models using a pericyte-expressed LacZ reporter transgene. The data indicate that loss of the pericyte marker is profoundly affected by Notch 3 deficiency. Previous studies with the XlacZ4 transgene revealed this marker is downregulated in response to vascular crush injury [11, 25], and thus loss of Notch 3 may be a perceived insult that promotes this event. Others and we have previously shown loss of Notch 3 promotes apoptosis in the retina $[16,23,39]$. Notch 3 haploinsufficiency and the Ins $2^{\text {Akita }}$ diabetic mice exhibited similar temporal profiles of LacZpositive pericytes and did not show an additive or cooperative effect in combination, which is surprising given they both contribute to pericyte loss. These data suggest that the XlacZ4 transgene may not be a suitable tool for monitoring pericyte loss due to its downregulation in response to various stressors.

Pericyte loss is a hallmark of diabetic retinopathy and is suggested to contribute to capillary degeneration in disease [13]. Using trypsin digest to assess acellular capillaries revealed that Notch 3 heterozygosity showed no significant difference in capillary degeneration at 24 weeks, while Ins $2^{\text {Akita }}$ diabetic mice exhibited a significant increase in acellular capillaries compared to wild-type control. Interestingly, combined Notch 3 haploinsufficiency and $I n s 2^{\text {Akita }}$ diabetes resulted in an additional increase in capillary degeneration, suggesting that perturbation of Notch3 likely diminishes the vascular protecting function of pericytes and therefore causes retinal capillaries to be more sensitive to diabetic conditions. Notch3 haploinsufficiency in diabetic mice does not affect pericyte loss but does affect the number of acellular capillaries, which is difficult to interpret. Possibly diabetes and haploinsufficiency both impair Notch signaling in pericytes, preventing an additive effect. However, this does not apply to the capillaries themselves, and there could be pericyte-independent functions of Notch3 that are responsible for capillary loss.

In examining Notch signaling components in retinas of diabetic mice, we evaluated Notch3 receptor and Jag1 ligand, which are known to play prominent roles in endothelial cell to mural cell (smooth muscle and pericytes) signaling $[35,36,40]$. At the transcript level, we observed no significant difference in Notch 3 expression between normal and diabetic retinal tissue, while Jag1 showed an increase in diabetic mice compared to controls (WT 0.99 \pm 0.291 , AK $1.378 \pm 0.769$ ). The increase in Jag1 is consistent with previous publications [41, 42], and indicates that diabetes may influence Notch signaling through altering the receptor/ligand ratio. Indeed, examination of known downstream targets of Notch signaling [34] showed varied differences, with Hes 1 and smooth muscle a-actin (Acta2) having decreased expression in diabetic mice indicative of reduced Notch activity (Hes1 WT 0.69 \pm 0.291, AK $0.32 \pm 0.335$, Acta 2 WT $0.86 \pm 0.798$, AK 0.51 $\pm 0.666)$; however, HeyL remained unchanged. This implies that diabetic effects on Notch signaling are not straightforward and may be indirect. Given that the retina is composed of an array of different cell types, it is difficult to assess whether these changes, or lack thereof, can be directly linked to Notch signaling in vascular cells. To address the direct effect of hyperglycemia on vascular cells, we utilized a previously published coculture model [36, 43] to evaluate Notch activity between endothelial cells and pericytes. Utilization of a Notch sensor luciferase construct transfected into retinal pericytes followed by coculture with retinal endothelial cells, we demonstrate robust endothelial cell-dependent Notch activation. Comparing Notch activity in normal glucose versus high glucose culture conditions, we observed hyperglycemia blunted the Notch signaling response. Thus, these data indicate that glucose affects Notch signaling, and this ability to perturb Notch signaling between endothelial cells and pericytes may be a contributing factor to pericyte loss in diabetes. Notch signaling has been directly linked to pericyte survival and support of the microcirculation $[14-17,23]$. These data are the first to demonstrate a link between Notch3 signaling and pericyte loss associated with diabetes. Our results suggest that disruption of endothelial cell-dependent Notch activity in pericytes may be a key contributor to pericyte dysfunction or loss. Further studies are needed to determine the causal relationship between hyperglycemia, Notch signaling, and pericyte dropout.

\section{Acknowledgments}

This work was supported by grants from the National Institutes of Health (R01HL132801 and R01HL135657 to B.L., EY022694 and EY026629 to W.Z.), Nationwide Children's Hospital (to B.L.), and the American Heart Association (17SDG33630151 to H.L.).

The authors thank Jackie Metheny and Caleb Priest for their contributions to this study. 


\section{Disclosure Statement}

The authors have no disclosures.

\section{Author Contributions}

H.L. and W.Z. performed experiments, analyzed and interpreted data, helped prepare, and edited the manuscript. B.L. performed experiments, analyzed and interpreted data, wrote and edited the manuscript.

\section{References}

1 Duh EJ, Sun JK, Stitt AW. Diabetic retinopathy: Current understanding, mechanisms, and treatment strategies. JCI Insight. 2017; 2(14):e93751.

2 Antonetti DA, Klein R, Gardner TW. Diabetic retinopathy. N Engl J Med. 2012 Mar; 366(13):1227-39

3 Zhang X, Saaddine JB, Chou CF, Cotch MF, Cheng YJ, Geiss LS, et al. Prevalence of diabetic retinopathy in the United States, 20052008. JAMA. 2010 Aug;304(6):649-56.

4 Lee R, Wong TY, Sabanayagam C. Epidemiology of diabetic retinopathy, diabetic macular edema and related vision loss. Eye Vis (Lond). 2015 Sep;2(17):17.

5 Beltramo E, Porta M. Pericyte loss in diabetic retinopathy: mechanisms and consequences. Curr Med Chem. 2013;20(26): 3218-25.

6 Pfister F, Przybyt E, Harmsen MC, Hammes HP. Pericytes in the eye. Pflugers Arch. 2013 Jun;465(6):789-96.

7 Motiejūnaite R, Kazlauskas A. Pericytes and ocular diseases. Exp Eye Res. 2008 Feb;86(2): $171-7$.

8 Stitt AW, Lois N, Medina RJ, Adamson P, Curtis TM. Advances in our understanding of diabetic retinopathy. Clin Sci (Lond) 2013;125:1-17.

9 Trost A, Lange S, Schroedl F, Bruckner D, Motloch KA, Bogner B, et al. Brain and Retinal Pericytes: Origin, Function and Role. Front Cell Neurosci. 2016 Feb 4;10:20.

10 Sweeney MD: Pericytes of the neurovascular unit: Key functions and signaling pathways. Nat Neurosci. 2016 May 26;19(6):771-83.

11 Armulik A, Genové G, Betsholtz C. Pericytes: developmental, physiological, and pathological perspectives, problems, and promises. Dev Cell. 2011 Aug;21(2):193-215.

12 van Dijk CGM, Nieuweboer FE, Pei JY, Xu YJ, Burgisser P, van Mulligen E, el Azzouzi H, Duncker DJ, Verhaar MC, Cheng C:

13 Arboleda-Velasquez JF, Valdez CN, Marko CK, D'Amore PA. From pathobiology to the targeting of pericytes for the treatment of diabetic retinopathy. Curr Diab Rep. 2015 Feb; 15(2):573.

14 Arboleda-Velasquez JF, Primo V, Graham M, James A, Manent J, D'Amore PA. Notch signaling functions in retinal pericyte survival. Invest Ophthalmol Vis Sci. 2014 Jul;55(8): 5191-9.
15 Ehling M, Adams S, Benedito R, Adams RH. Notch controls retinal blood vessel maturation and quiescence. Development. $2013 \mathrm{Jul}$; 140(14):3051-61.

16 Henshall TL, Keller A, He L, Johansson BR, Wallgard E, Raschperger E, et al. Notch3 is necessary for blood vessel integrity in the central nervous system. Arterioscler Thromb Vasc Biol. 2015 Feb;35(2):409-20.

17 Wang Y, Pan L, Moens CB, Appel B. Notch3 establishes brain vascular integrity by regulating pericyte number. Development. 2014 Jan;141(2):307-17.

18 Domenga V, Fardoux P, Lacombe P, Monet M, Maciazek J, Krebs LT, et al. Notch3 is required for arterial identity and maturation of vascular smooth muscle cells. Genes Dev. 2004 Nov; 18(22):2730-5.

19 Joutel A, Corpechot C, Ducros A, Vahedi K, Chabriat $\mathrm{H}$, Mouton $\mathrm{P}$, et al. Notch3 mutations in CADASIL, a hereditary adult-onset condition causing stroke and dementia. $\mathrm{Na}$ ture. 1996 Oct;383(6602):707-10.

20 Arboleda-Velasquez JF, Manent J, Lee JH, Tikka S, Ospina C, Vanderburg CR, et al. Hypomorphic Notch 3 alleles link Notch signaling to ischemic cerebral small-vessel disease. Proc Natl Acad Sci USA. 2011 May; 108(21):E128-35.

21 Claxton S, Fruttiger M. Periodic Delta-like 4 expression in developing retinal arteries. Gene Expr Patterns. 2004 Nov;5(1):123-7.

22 Hofmann JJ, Luisa Iruela-Arispe M. Notch expression patterns in the retina: an eye on receptor-ligand distribution during angiogenesis. Gene Expr Patterns. 2007 Feb;7(4): 461-70.

23 Liu H, Zhang W, Kennard S, Caldwell RB, Lilly B. Notch3 is critical for proper angiogenesis and mural cell investment. Circ Res. 2010 Oct;107(7):860-70.

24 Kofler NM, Cuervo H, Uh MK, Murtomäki A, Kitajewski J. Combined deficiency of Notch 1 and Notch 3 causes pericyte dysfunction, models CADASIL, and results in arteriovenous malformations. Sci Rep. 2015 Nov;5(1):16449.

25 Tidhar A, Reichenstein M, Cohen D, Faerman A, Copeland NG, Gilbert DJ, et al. A novel transgenic marker for migrating limb muscle precursors and for vascular smooth muscle cells. Dev Dyn. 2001 Jan;220(1):6073.
26 Barber AJ, Antonetti DA, Kern TS, Reiter CE, Soans RS, Krady JK, et al. The Ins2Akita mouse as a model of early retinal complications in diabetes. Invest Ophthalmol Vis Sci. 2005 Jun;46(6):2210-8.

27 Han Z, Guo J, Conley SM, Naash MI. Retinal angiogenesis in the Ins2(Akita) mouse model of diabetic retinopathy. Invest Ophthalmol Vis Sci. 2013 Jan;54(1):574-84.

28 Kador PF, Zhang P, Makita J, Zhang Z, Guo C, Randazzo J, et al. Novel diabetic mouse models as tools for investigating diabetic retinopathy. PLoS One. 2012;7(12):e49422.

29 Pfister F, Feng Y, vom Hagen F, Hoffmann S, Molema G, Hillebrands JL, et al. Pericyte migration: a novel mechanism of pericyte loss in experimental diabetic retinopathy. Diabetes. 2008 Sep;57(9):2495-502.

30 vom Hagen F, Feng Y, Hillenbrand A, Hoffmann S, Shani M, Deutsch U, et al. Early loss of arteriolar smooth muscle cells: More than just a pericyte loss in diabetic retinopathy. Exp Clin Endocrinol Diabetes. 2005 Dec; 113(10):573-6.

31 Gurel Z, Sieg KM, Shallow KD, Sorenson CM, Sheibani N. Retinal O-linked N-acetylglucosamine protein modifications: Implications for postnatal retinal vascularization and the pathogenesis of diabetic retinopathy. Mol Vis. 2013 May; 19:1047-59.

32 Toque HA, Nunes KP, Yao L, Xu Z, Kondrikov D, Su Y, et al. Akita spontaneously type 1 diabetic mice exhibit elevated vascular arginase and impaired vascular endothelial and nitrergic function. PLoS One. 2013 Aug; 8(8):e72277.

33 Shin ES, Sorenson CM, Sheibani N. Diabetes and retinal vascular dysfunction. J Ophthalmic Vis Res. 2014 Jul-Sep;9(3):362-73.

34 Siebel C, Lendahl U. Notch Signaling in Development, Tissue Homeostasis, and Disease. Physiol Rev. 2017 Oct;97(4):1235-94.

35 Ji Y, Chen S, Xiang B, Li Y, Li L, Wang Q: Jagged1/Notch3 Signaling Modulates Hemangioma-Derived Pericyte Proliferation and Maturation. Cell Physiol Biochem. 2016;40: 895-907.

36 Liu H, Kennard S, Lilly B. NOTCH3 expression is induced in mural cells through an autoregulatory loop that requires endothelialexpressed JAGGED1. Circ Res. 2009 Feb; 104(4):466-75. 
37 Krebs LT, Xue Y, Norton CR, Sundberg JP, Beatus P, Lendahl U, et al. Characterization of Notch3-deficient mice: normal embryonic development and absence of genetic interactions with a Notch1 mutation. Genesis. 2003 Nov;37(3):139-43.

38 Lin $\mathrm{CH}$, Lilly $\mathrm{B}$. Notch signaling governs phenotypic modulation of smooth muscle cells. Vascul Pharmacol. 2014 Nov;63(2):8896.
39 Machuca-Parra AI, Bigger-Allen AA, Sanchez AV, Boutabla A, Cardona-Vélez J, Amarnani $\mathrm{D}$, et al. Therapeutic antibody targeting of Notch3 signaling prevents mural cell loss in CADASIL. J Exp Med. 2017 Aug; 214(8):2271-82.

40 Gridley T. Notch signaling in the vasculature. Curr Top Dev Biol. 2010;92:277-309.

41 Yoon CH, Choi YE, Cha YR, Koh SJ, Choi JI, Kim TW, et al. Diabetes-Induced Jagged 1 Overexpression in Endothelial Cells Causes Retinal Capillary Regression in a Murine Model of Diabetes Mellitus: Insights Into Diabetic Retinopathy. Circulation. 2016 Jul; 134(3):233-47.
42 Yoon CH, Choi YE, Koh SJ, Choi JI, Park YB, Kim HS. High glucose-induced jagged 1 in endothelial cells disturbs notch signaling for angiogenesis: A novel mechanism of diabetic vasculopathy. J Mol Cell Cardiol. 2014 Apr; 69:52-66.

43 Lilly B, Kennard S. Differential gene expression in a coculture model of angiogenesis reveals modulation of select pathways and a role for Notch signaling. Physiol Genomics. 2009 Jan;36(2):69-78. 